Considering the data showed significantly different between two groups in mental health, Somatic symptoms, Anxiety and Sleep Disorder and Social Function ( $p>0.005)$. But in Depression symptoms didn't $t$ showed significantly different between two groups $(p<0.05)$. These results showed participation in sports activities have significant effects on mental health. In the other hand evolution the score of students participating in sports programmes than the students no participating was showed they (G1) have a better condition in mental health and other variables. Participating in sports activities regularly have caused physiological adaptations such as respiratory, musculoskeletal, cardiovascular and hormonal adaptations so will promote individual capabilities in physical and mental level and enhance the tolerant of the people versus oppressions of the environment and this point prevented of mental disorder.

\title{
202 STUDY THE EFFECT OF PARTICIPATION IN PHYSICAL ACTIVITY ON MENTAL HEALTH
}

Lena Motallebi M S, Mahvash Noorbakhsh ${ }^{1}$ Islamic Azad University, Shushtar Branch, Iran; ${ }^{2}$ Islamic Azad University, Karaj Branch, Iran

\subsection{6/bjsm.2010.078725.202}

According to the WHO experts more than 150 million of the world populations are suffering of nervous, psychological and social disorders. Expansion of urban society and consequently to the intensive human life in the urban framework and increased social communications, elimination of place and nature of the life in the city, the prime mover of diverse pressures on psyche of the human. New research shows that physical exercises have increased the ability of the brain and also assist peoples in the treatment of mental illnesses such as depression and anxiety. In fact have been advised to psychiatrists change their clinical methods and drug cures and set participate in physical activities in the programme's treatment their patients.

In this research have been assessed mental health and four scales including, Somatic symptoms, Anxiety and Sleep disorder, Depression symptoms and Social Function by GHO questionnaire. Data have been analysed by t test with $\alpha=0.05$. In this study participated 200 students (M, F). Group 1: 100 of students (mean age 24.51, _ \pm 5.03 SD) participate in the University Sport Programs and group 2: 100 students (mean age $22.91, \pm 2.80 \mathrm{SD}$ ) don't participate in any sport activities. 